\title{
Database Narrative in Book and Online
}

Johanna Drucker

BiB 2014 


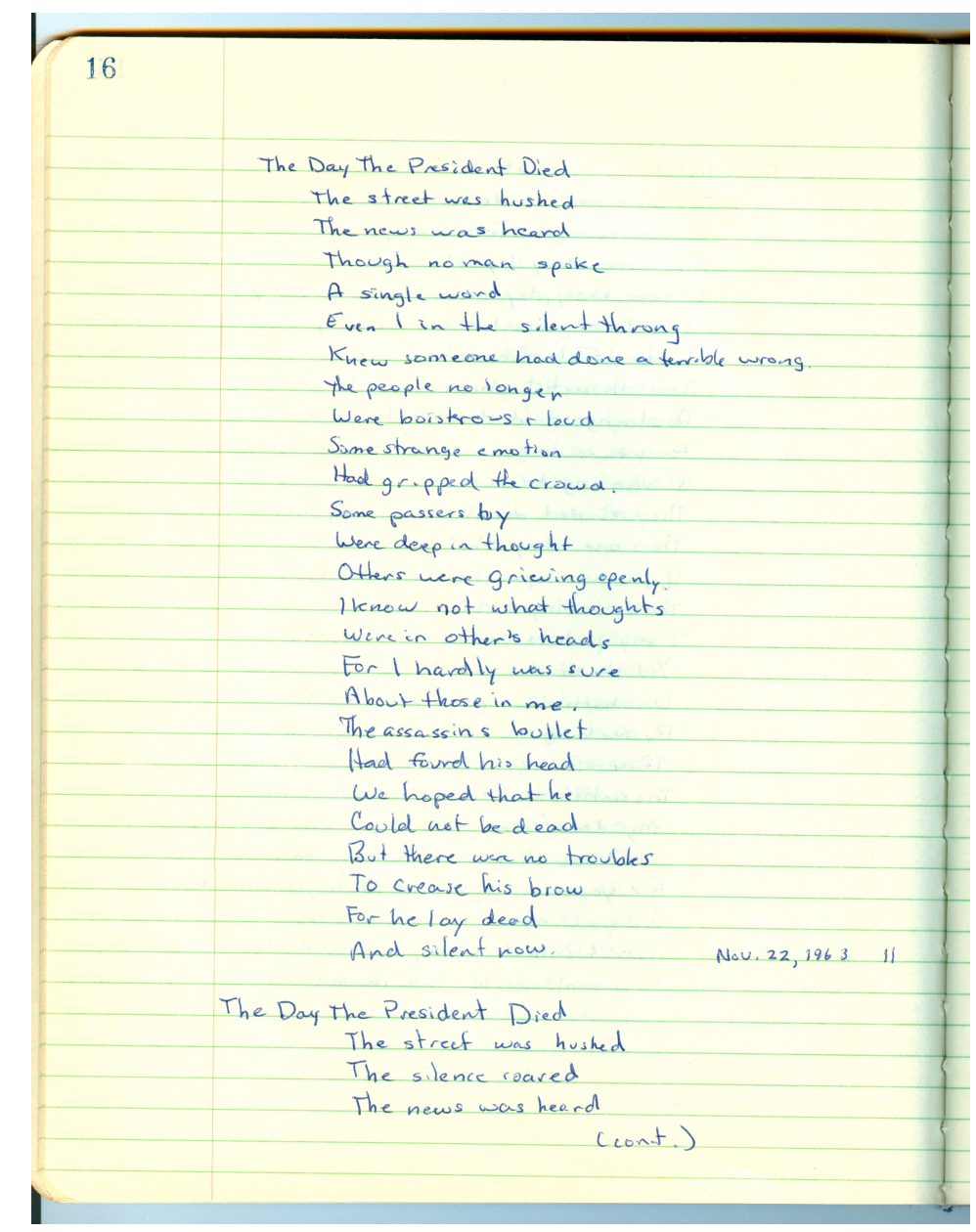




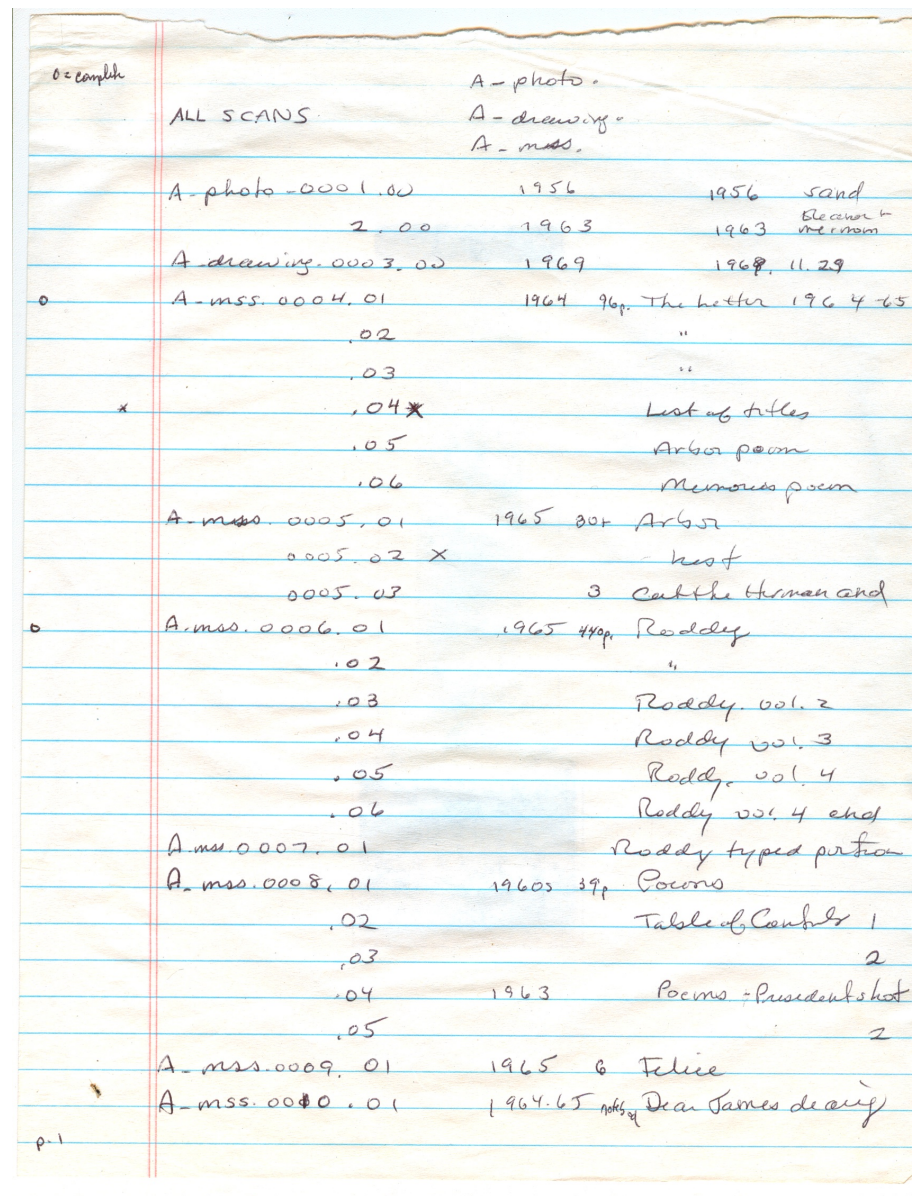




\begin{tabular}{|c|c|c|c|c|c|c|c|c|c|c|}
\hline$\infty$ & A & B & C & D & $\mathbf{E}$ & $\mathbf{F}$ & G & H & \multirow{3}{*}{$\frac{\text { I }}{\text { Section }}$} & \multirow[b]{2}{*}{ XML d } \\
\hline 1 & Title of Manuscript & Description & Date & Place & Scan ID & Pages & \multicolumn{2}{|c|}{ MssComplete WorkComplete } & & \\
\hline 2 & & & & & & & & & & \\
\hline 3 & Drawing & Bald child, pencil drawing & 1969 & Philadelphia & A_drawing_0003_00 & 1 & $\mathrm{Y}$ & & 2 & \\
\hline 4 & Drawing & Drawings / originals & 1982 & Oakland & A_drawing_0084_01 & 1 & Y & & & \\
\hline 5 & The Letter & Page & 1964 & Philadelphia & A_mss_0004_01 & 96 & $\mathrm{Y}$ & & 1 & \\
\hline 6 & The Letter & Page & & & A_mss_0004_02 & & & & 1 & \\
\hline 7 & The Letter & Page & & & A_mss_0004_03 & & & & 1 & \\
\hline 8 & The Letter & List of titles & & & A_mss_0004_04 & & & & 1 & \\
\hline 9 & The Letter & Arbor poem & & & A_mss_0004_05 & & & & 1 & \\
\hline 10 & The Letter & Memories poem & & & A_mss_0004_06 & & & & 1 & \\
\hline 11 & The Arbor & Page & 1965 & Philadelphia & A_mss_0005_01 & 30 & $\mathrm{~N}$ & & 1 & \\
\hline 12 & The Arbor & List of titles & 1965 & Philadelphia & A_mss_0005_02 & & & & 1 & \\
\hline 13 & The Arbor & Cat the Herman and & 1965 & Philadelphia & A_mss_0005_03 & 3 & Y & & 1 & \\
\hline 14 & Roddy & Page & 1965 & Philadelphia & A_mss_0006_01 & 440 & $\mathrm{Y}$ & & 1 & \\
\hline 15 & Roddy & Interior page & 1965 & Philadelphia & A_mss_0006_02 & & & & 1 & \\
\hline 16 & Roddy. Volume 2 & Page & 1965 & Philadelphia & A_mss_0006_03 & & & & 1 & \\
\hline 17 & Roddy, Volume 3 & Page & 1965 & Philadelphia & A_mss_0006_04 & & & & 1 & \\
\hline 18 & Roddy, Volume 4 & Page & 1965 & Philadelphia & A_mss_0006_05 & & & & 1 & \\
\hline 19 & Roddy, Volume 4, end & Final page & 1965 & Philadelphia & A_mss_0006_06 & & & & 1 & \\
\hline 20 & Roddy, typed portion & First pages & 1965 & Philadelphia & A_mss_0007_01 & & $\mathrm{N}$ & & 1 & \\
\hline 21 & Poems & Fair copy & 1960 s & Philadelphia & A_mss_0008_01 & 39 & $\mathrm{Y}$ & & 1 & \\
\hline 22 & Poems & Table of contents & $1960 \mathrm{~s}$ & Philadelphia & A_mss_0008_02 & & $\mathrm{Y}$ & & 1 & \\
\hline 23 & Poems & Pages & 1960 s & Philadelphia & A_mss_0008_03 & & Y & & 1 & \\
\hline 24 & Poems & The day the President was shot & 1963 & Philadelphia & A_mss_0008_04 & & Y & & 1 & \\
\hline 25 & Poems & The day the President was shot & 1963 & Philadelphia & A_mss_0008_05 & & $\mathrm{Y}$ & & 1 & \\
\hline 26 & Felice & Page & 1965 & Philadelphia & A_mss_0009_01 & 6 & $\mathrm{Y}$ & & 1 & \\
\hline 27 & Dear James Diary & Page of notebook & $1964-65$ & Philadelphia & A_mss_0010_01 & & $\mathrm{Y}$ & & 1 & \\
\hline 28 & Mirror Mirror & Page & $1965-66$ & Philadelphia & A_mss_0011_01 & 7 & $\mathrm{Y}$ & & 1 & \\
\hline 29 & Mirror Mirror & Page of inside text & $1965-66$ & Philadelphia & A_mss_0011_02 & 7 & $\mathrm{Y}$ & & 1 & \\
\hline 30 & Mirror Mirror, other & Page & $1965-66$ & Philadelphia & A_mss_0012_01 & 4 & $\mathrm{Y}$ & & 1 & \\
\hline 31 & Poems (November) & Page & $1967-68$ & Philadelphia & A_mss_0013_01 & 4 & $\mathrm{Y}$ & & 2 & \\
\hline 32 & Prose Mss. & Pages & 1968 & Philadelphia & A_mss_0014_01 & 32 & $\mathrm{Y}$ & & 2 & \\
\hline 33 & Novel 1964 & Pages typed & $1965-5$ & Philadelphia & A_mss_0015_01 & 54 & $\mathrm{Y}$ & & 2 & \\
\hline 34 & Novel 1964 & Page of inside text & $1965-66$ & Philadelphia & A_mss_0015_02 & 54 & $Y$ & & 2 & \\
\hline 35 & Novel 1964 & Page of inside text & $1965-66$ & Philiadelphia & A_mss_0015_03 & 54 & $\mathrm{Y}$ & & 2 & \\
\hline
\end{tabular}




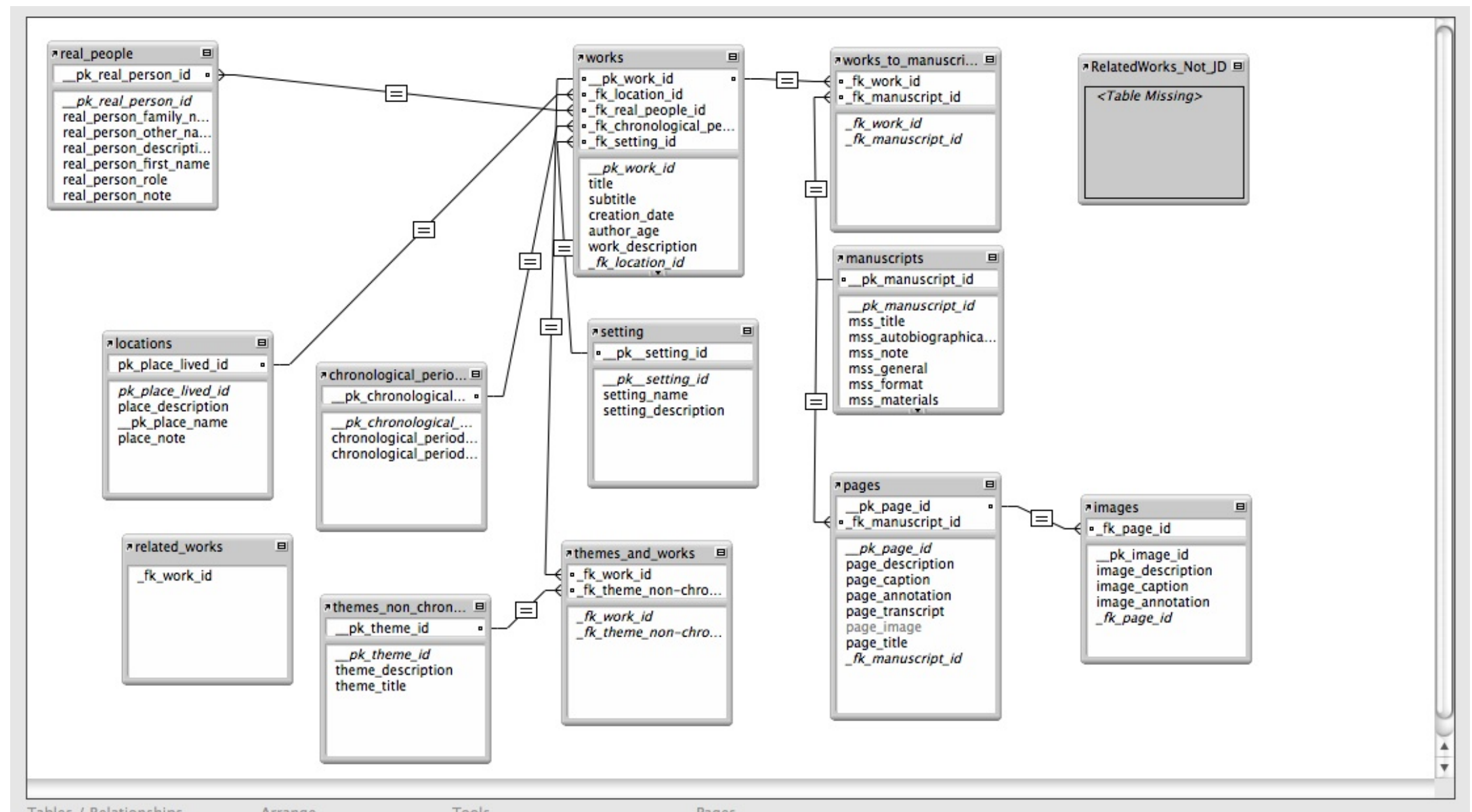




\section{ALL: Database}

\section{(primary tables and preset information)}
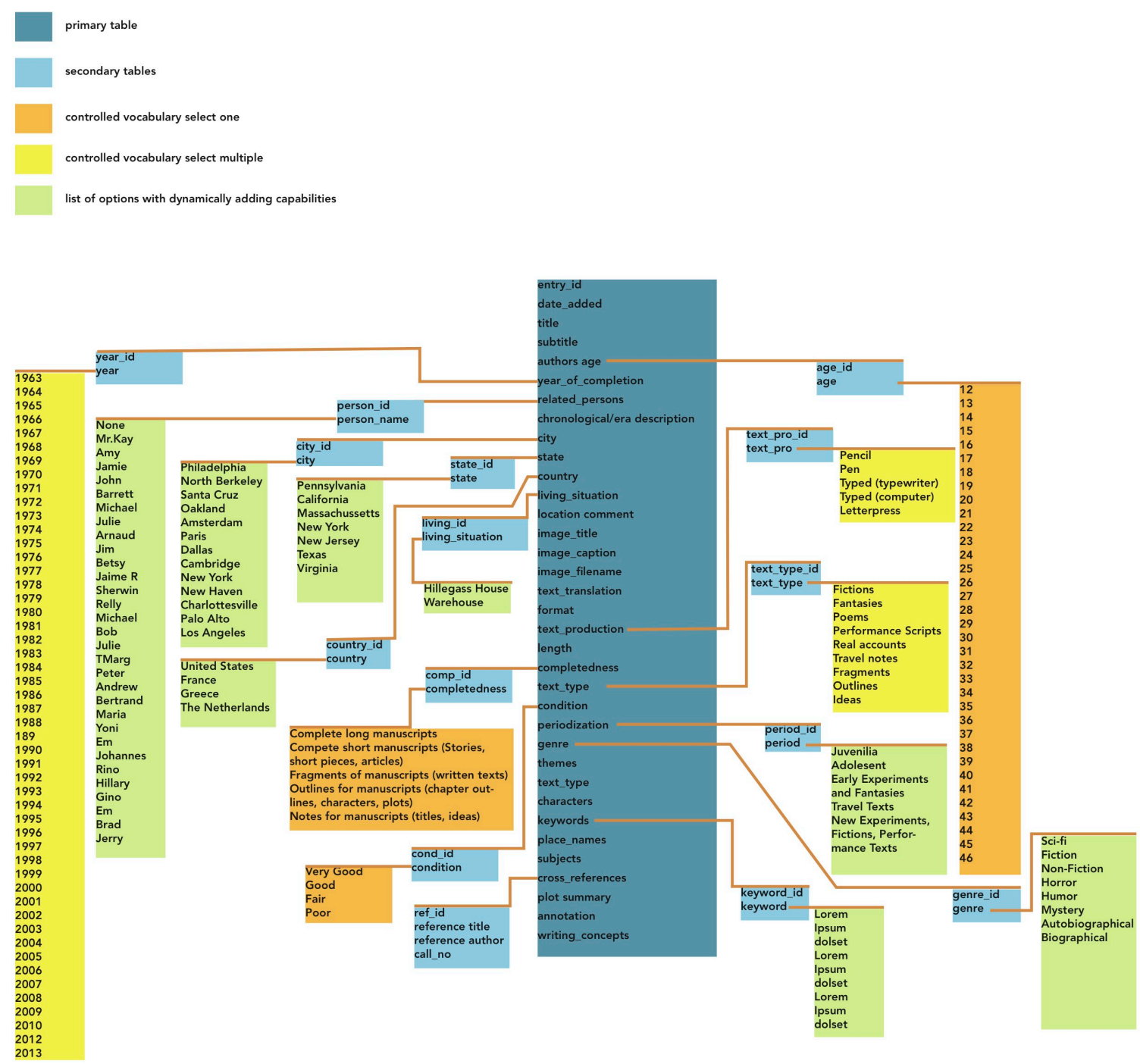


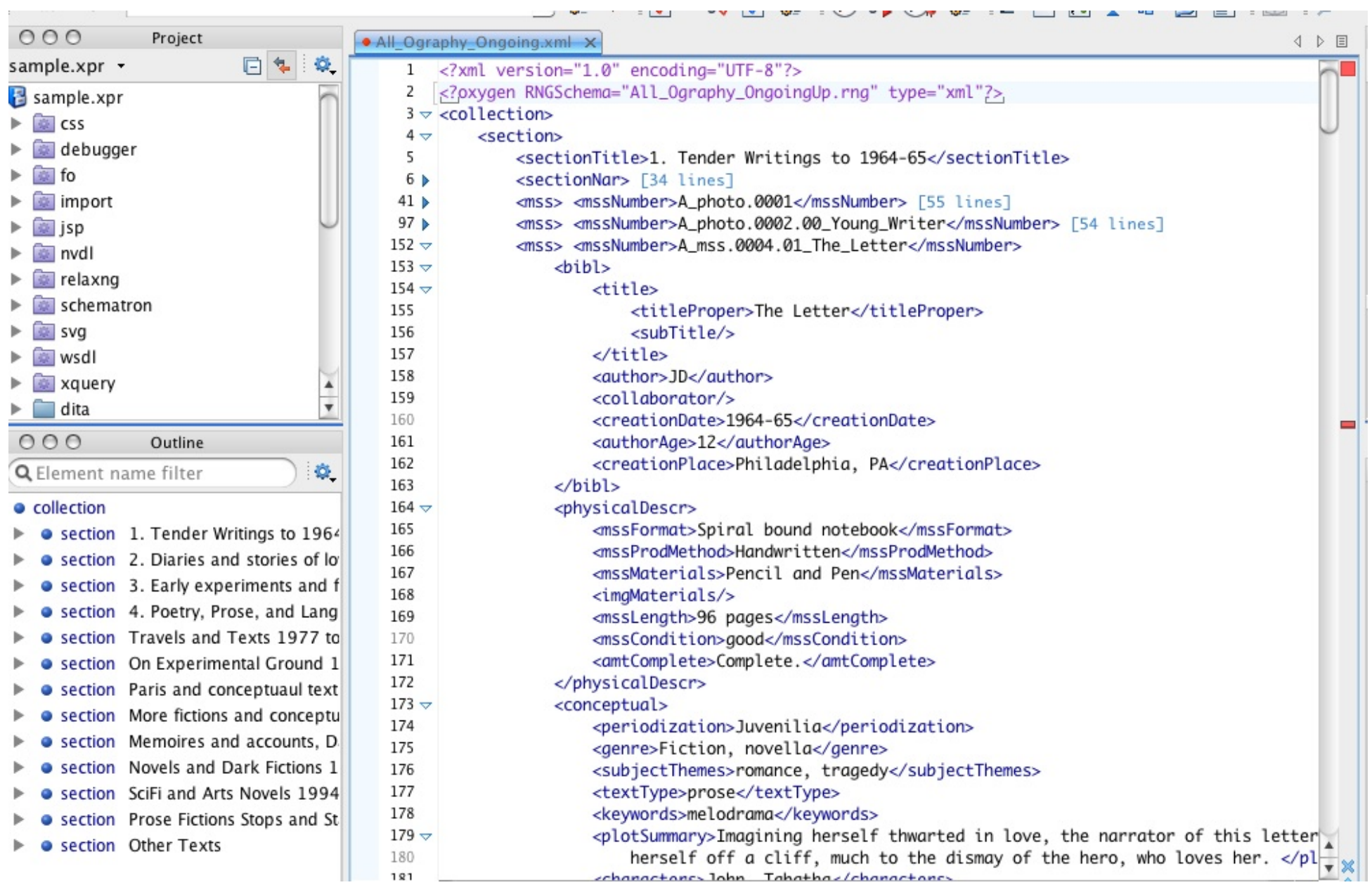




\section{ALL Chronology Place Theme Genre Title Index}

Pupa House / 1972 / Prose / Fantasy Fiction

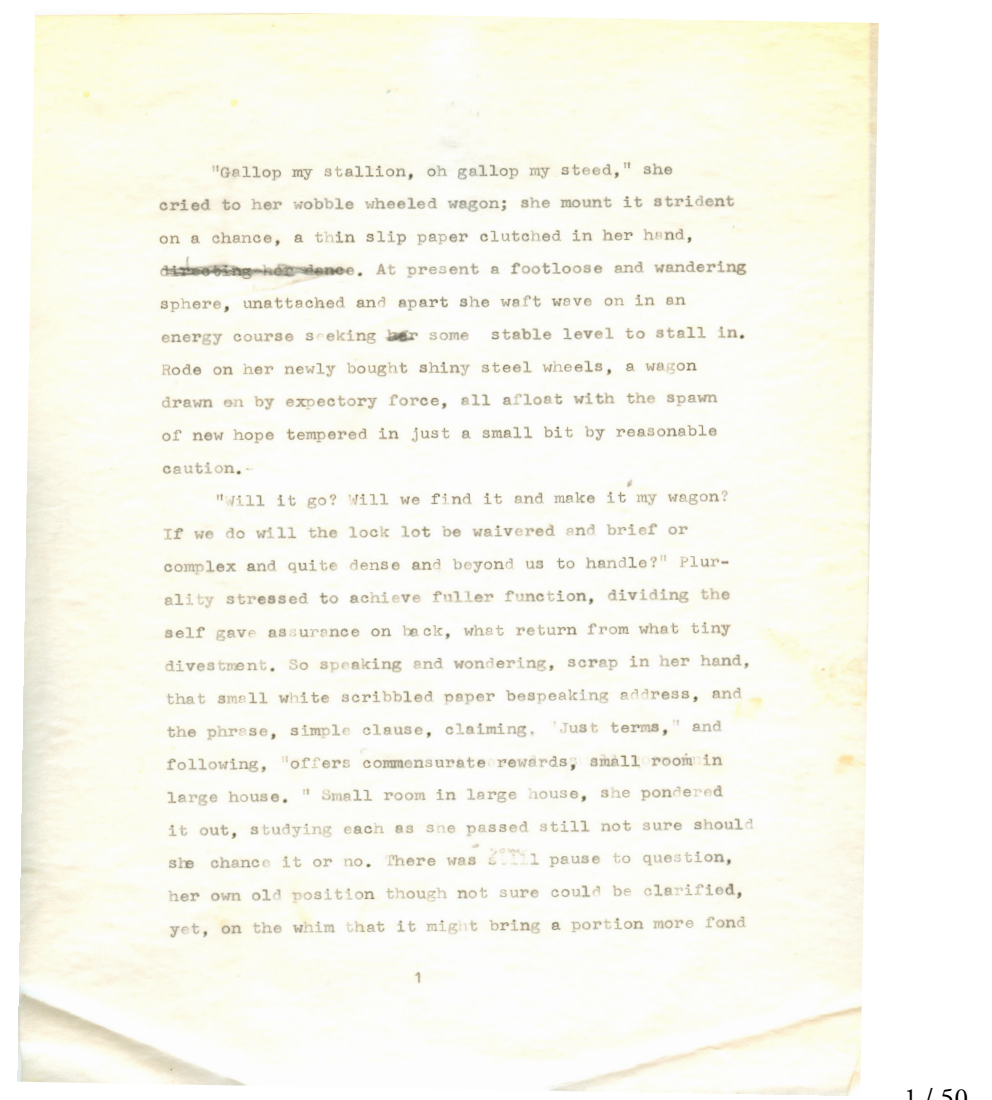

Ms. 0033x_01; typescript, 50 pages, $81 / 2 \times 11$ "; loose sheets, numbered; good condition; if a handwritten version existed, it is long gone, along with any notes; but the illustrations for this work exist. It was written out, not corrected, so the pencil cancellations standout as unusual.

It may have been typed on the portable Brother typewriter I had bought at age 12 for Xmas, half from my babysitting money ( $\$ .50$ an hour), half subsidized by my mother. I recall it cost nearly $\$ 70$, an enormous sum. Does it match the typescripts of my Philadelphia adolescent days?
Oakland, California / Hillegass / Early adulthood / Jamie

I am in California. The sheer exoticism of the blooms everywhere on the streets and yards overwhelms me. Their color is all excess and extravagance. Nature seems to squander beauty with a complete disregard for decorum. The restrained seasons of Philadelphia, and the urban landscapes of childhood offer no preparation for fuschia, roses, wisteria, clematis, and poppies in their endless display. I hardly know what to think, riding my newly bought bicycle, my body is still young, thick, slumbering, and unprepared for assaults on the senses. I have been in the Hillegass house for a year. I am encoding the encounters in language that veils the experiences, masks them, keeps them from view. I am not willing to state anything directly. The same modesty that is shocked by the wantonness of flowers is engaged in the obfuscation of statements through double entendre and puns, the combination of displacements and condensations that make mere description into metaphor.

The manuscript sings, its rhythms more nursery than adult. "Small room in large house, she pondered it out." The antiquarian quality of vocabulary is as striking as the rhymes. I am steeped in the language of 19th century fiction. The compressions and abbreviations of modern writing have not had an influence or taken hold. Some of the spare leanness of adolescent composition has been forgotten, repressed, along with recollections of Amy. In this new phase of pre-adult encapsulation, writing is antique, mannered, contrived, an infantile archaism, borrowed from literary relics of an already other era. Life lived through its complex figurings is equally ornamental, serving as surface, shield, and screen. But this is 1970 , and the house where I rent a small room is filled with undergraduate students who go to Berkeley. I am in an art school whose tiny campus is located on a small knoll of a hill in Oakland, where College Avenue meets Broadway. I ride my bicycle every day, unless it rains, and trudging up the path pushing the handlebars is almost as much as I can manage. I am not a physical creature, not yet. My body is sleeping, and my fears hem me in at every turn. I am shy around the young men who are my roommates, wondering who among them will or might become my lover. Boyfriend. Sweetheart. The very question of terminology has its own torments.

A story of intrigue and romance, social relations, with characters and plots thinly concealing the actual people in the house. The story is meant to show the cross-currents and subtexts of their exchanges, rather than the surface level of engagements or exchange, as if reading the emotional shifts of energy at a dream-state of subconscious inention revealed as metaphor rather than in the explicit words. Writing life.

MORE...

Related to Oh Oh 1973-74, Whole 1971-72. 
- $\underline{\text { ALL Project }}$

- ALL the books

- Introduction

\section{Introduction}

Submitted by JohannaDrupall on Mon, 08/18/2014 - 10:21

Introduction: This site contains representative images of manuscripts, interpretative notes, and supplementary materials about the 400 or so book and never published, or began and did not finished, or only sketched in outline. For completed manuscripts, the pdf is attached as a downloadab cases, additional page level interpretative materials are present, and all

Contents:

By Chronology Titles Genres Writing Concepts Themes

\section{$\underline{\text { Read more }}$}

\section{Test of PDF upload}

Submitted by JohannaDrupall on Wed, 10/09/2013 - 16:53

This is a pdf of a book manuscript written in the 1960s.

Read more 
This site contains representative images of manuscripts, interpretative notes, and supplementary materials about the 400 or so books I either wrote and never published, or began and did not finished, or only sketched in outline. For completed manuscripts, the pdf is attached as a downloadable file. In some cases, additional page level interpretative materials are present.

right: Bubblegirl, 197X

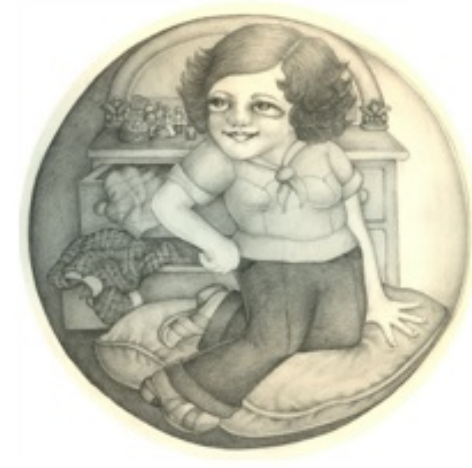

\section{SEARCH BY:}

\begin{tabular}{l} 
CHRONOLOGY \\
$1962-1965$ \\
$1965-69$ \\
$1969-70$ \\
$1970-77$ \\
$1970-75$ \\
$1975-77$ \\
$1977-79$ \\
$1979-84$ \\
$1984-85$ \\
$1985-86$ \\
$1986-88$ \\
1989 \\
$1990-94$ \\
$1994-99$ \\
$1999-2008$ \\
$2008-2010$ \\
$2010-2014$ \\
\hline
\end{tabular}

\section{TITLE}

Against Fiction Agony and Ecstasy Art's History Baby outline Blank Minded Murder Business notes, Otis etc.

City Paper

Claustrophobia Detail Center Diary notebooks Dreamlife and Desire Family Accounts Family Life Fintion

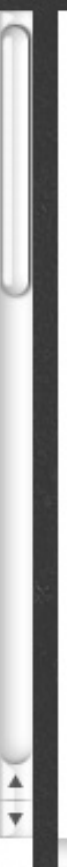

GENRE
Poetry
Prose
Fantasy Fiction
Genre Genre
Genre
Genre
GenreGenre
Genre
Genre
Genre
GenreGenre
Genre
GenreGenre
Genre
GenreGenre
Genre
Ganreranre

CONCEPTS
Concepts
Concepts
Concepts
ConceptsConcepts
Concepts
ConceptsConcepts
Concepts
Concepts
Concepts
ConceptsConcepts
Concepts
ConceptsConcepts
Concepts
Concepts
Concepts
Concepts
Concents Concents

THEMES

Themes

Themes

ThemesThemes

Themes

Themes

Themes

Themes

ThemesThemes

Themes

Themes

ThemesThemes

Themes

Themes

Themes

Themes

Themes

Themesthemec 


\section{...the books I never wrote}

or wrote and never published

This online site accompanies the book All, or which serves as acontain full PDFs of all the manuscripts, longer accounts, and more detailed discussions as well as the links and relations that are structured into the database format.

This is a book about books. All the books I wrote and never published are here, along with the notes, outlines, beginnings and scraps of the books begun and never finished. Some are solid objects, fully formed, finished, waiting for exposure and the chance to rise from their oblivion. Others were abandoned, and stand like wraiths, orphans of a transitory impulse. Others are merely the trace of a possible tale, potential, outlines, notes, or ideas for projects that never went beyond that title, or phrase, or list of chapters.

Each is evidence of a moment in personal and cultural time, the intersection of interior life and actual circumstances. Each is testimony to an idea of writing, what it should be, whether poem or prose, diary or novel, fiction or account of some experience. I've tried to write about them in this wav in an autn-arrhaenloov attentive to their materialitv

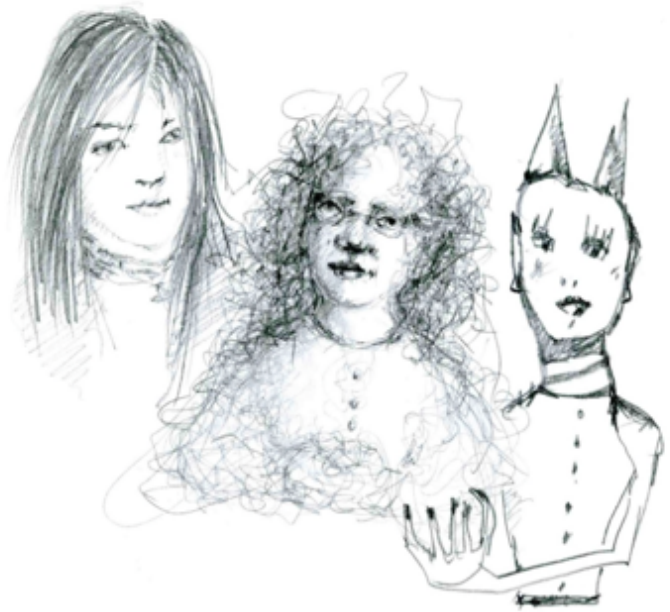


16

The Day, the Basident Died

The stireet wes huthed

The news was hereral

Theurgh min anches sperieg

A singyte wiod

Even in the sileret the rax

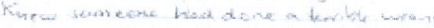

The plisple ate tougen

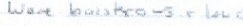

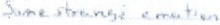

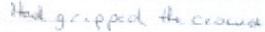

Some peistert by

then deep on thewerst

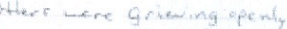

know not what theought.

Wise in otherts heads

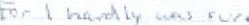

Alwath these in ane

The aseassins soullet

Heat fiuct his head

Whe haped that he

Cauld unct be de a and

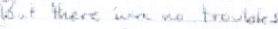

To creanic his brow

For he loy diend

The Day the President Died

The steet whs hothed

The slance sared

The news was her..

liant $)$

Mss_00140_000; 30 pages; in a hard-cover copy book covered with blue canvas. In very good condition. This is a fair copy of the poems, whose originals are long gone. I do not recall when the copy was made, but not much later than 1968 or 1969 , by the printed handwriting, which is carefu but with a slight back slant, the use of the ledgernotebook, and the pen.

The poems were written in Philadelphia, in my childhood home. This page contains one of several poems written the day John F. Kennedy was shot. I don't have any other manuscripts from this period, and none in their originals until a year later.

Poetry was the highest art, the only literary form that really mattered. Drama second. Prose was of the world, and admirable, but not the same stature as poetry, though the great novels were respected, and novelists.
November 22, 1963, they let us out of school early. I go to Masterman, the elementary and middle school with its gifted tracks. Many of the kids in my neighborhood go there too, though the school is a magnet school and draws from all over the city. I am not allowed to have playdates with friends unless they are in our neighborhood. My mother works and will not drive us to the suburbs or to remote parts of Philadelphia. So on this day, strange and disorienting day, I take the two city busses, one from 17th and Spring Garden to 17th and Spruce, where I wait for the 90. I think it must be a very old bus, it comes slowly, and they never use the newer models on the route. Why don't I walk the five blocks? I'm not sure. The habit is to wait on the corner by the drugstore. Sometimes, but rarely, I go into the store and buy candy, usually the pink and white covered licorice candies in a small rectangular box, Good and Plenty. They last longer than other candies because they are small, and suckable, and when the sugar coating is off, the licorice pellets in the core stick to the back teeth and melt slowly. I like to lie on my bed reading on my stomach with the taste of sugar stretching through the afternoon. But I am shy and rarely go into the store, and also, I do not have extra money. I have thirty-five cents for lunch each day and that is for my "tray" which is put together in the cafeteria line. Juice in a pleated paper cup. Food from the steam table served by jowled heavy women whose skin reminds me of sliced lunch meat, mottled, spotted, pale. The steam seems to make them flaccid. Their arms hang and wobble. They are big women, cafeteria workers, but they supervise us with sharp words and the disciplines of the line are part of the school routine.

On this strange afternoon all normalcy is suspended. The streets are filled with people in shock. I know our president is young and handsome, with a fashionable wife, but my mother is critical of him, thinks he is too hawkish, and my father always reminds her his family were bootleggers in the Depression, and that they made their fortune illegally. My parents are radical thinkers. My mother has an edge. Whatever she sees in the newspaper she comments on as if the news were only a cover for events going unreported. She and my father seem know things the news does not, and though they agree, she is the one who sees farther, speaks more sharply, critically. I go to Masterman, the elementary and middle school with its gifted tracks. Many of the kids in my neighborhood go there too, though the school is a magnet school and draws from all over the city. I am not allowed to have playdates with friends unless they are in our neighborhood. My mother works and will not drive us to the suburbs or to remote parts of Philadelphia. So on this day, strange and disorienting day, I take the two city busses, one from 17th and Spring Garden to 17 th and Spruce, where I wait for the 90. I think it must be a very old bus, it comes slowly, and they never use the newer models orthe route 